\title{
El debate sobre la ley 27.275 y la exigencia del acceso a la información en Argentina
}

\author{
The debate about the Law 27.275 and the demand \\ for access to information in Argentina
}

$O$ debate sobre a Lei 27.275 e a exigência de acesso à informação na Argentina

Le débat sur la loi 27.275 et lèxigence d'accès à l'information en Argentina

关于阿根廷第27275号法律和获取信息的要求的辩论

Elena Espin Di Febo ${ }^{1}$ Universidad Nacional de Río Negro, Javier Torres Molina ${ }^{2}$ Argentina

Revista Derechos en Acción ISSN 2525-1678/ e-ISSN 2525-1686

Año 4/No 13, Primavera 2019 (21 septiembre a 20 diciembre), 307-344

DOl: https://doi.org/10.24215/25251678e340

ORCID: https://orcid.org/0000-0001-5072-8161

https://orcid.org/0000-0002-3237-781X

Recibido: 07/06/2019

Aprobado: 25/09/2019

Resumen: El objetivo del presente trabajo es analizar el texto de la Ley de Acceso a la Información n ${ }^{0} 27.275$ que se sancionó en el año 2016. En ese sentido, nuestra intención es describir el contenido del texto legal, haciendo hincapié en los aspectos más fundamentales de la normativa, pero también se revisará el proceso legislativo que tuvo la mencionada norma. Es decir, se analizará el texto finalmente sancionado y las diferentes posturas que se desarrollaron en la discusión parlamentaria que originaron diferentes dictámenes y opiniones por parte de distintos legisladores. Asimismo, también nos referiremos a opiniones que varios

\footnotetext{
1 Universidad Nacional de Río Negro, elenaespindifebo@gmail.com

2 CIEDIS/UNRN Becario PERHID-CIN, Doctorando en Comunicación, UNLP. jtorresmolina@ unrn.edu.ar
} 
colectivos relacionados con la comunicación y el derecho han manifestado en torno a la ley de acceso a la información. Para realizar la descripción, consideramos necesario primero analizar conceptualmente el derecho de acceso a la información, entendiendo que dicho concepto no es operativo sólo para quienes se desempeñan en los medios de comunicación social, sino que su ejercicio pleno a través de la garantía estatal redunda en un mayor y mejor ejercicio de la ciudadanía.

Palabras claves: acceso a la información - derecho a la información participación política - ciudadanía

Abstract: The objective of this paper is to analyze the text of the Access to Information Law No. 27.275 that was enacted in 2016. In this sense, our intention is to describe the content of the legal text, emphasizing the most fundamental aspects of the regulation, but we will also review the legislative process that this regulation had. That is to say, the text finally sanctioned and the different positions that were developed in the parliamentary discussion that originated different opinions and opinions on the part of different legislators will be analyzed. Likewise, we will also refer to opinions that various groups related to communication and law have expressed regarding the law on access to information. In order to carry out the description, we consider it necessary first to analyze conceptually the right of access to information, understanding that this concept is not only operative for those who work in the media, but that its full exercise through the state guarantee results in a greater and better exercise of citizenship.

Keywords: Acceso to Information - Right to information - Political Participation - Citizenship

Resumo: 0 objetivo deste artigo é analisar 0 texto da Lei de Acesso à Informação n ${ }^{0} 27.275$ que foi sancionada no ano 2016. Nesse sentido, nossa intenção é descrever o conteúdo do texto jurídico, enfatizando os aspectos mais fundamentais da normativa, mas o processo legislativo que tinha a norma mencionada também será revisado. Isto é, serão analisado 0 texto finalmente sancionado e as diferentes posições que foram desenvolvidas na discussão parlamentar que originaram diferentes opiniões de diferentes legisladores. Da mesma forma, também nos referiremos a opiniões que vários grupos relacionados com a comunicação e 0 direito expressaram sobre a lei do acesso à informação. Para fazer a 
descrição, consideramos necessário primeiro analisar conceitualmente 0 direito de acesso à informação, entendendo que esse conceito não é operativo apenas para quem trabalha nos meios de comunicação social, senão que seu pleno exercício através da garantia estatal resulta em um maior e melhor exercício da cidadania.

Palavras-chave: acesso à informação - direito à informação - participação política-cidadania

Résumé: L'objectif de ce travail est d'analyser le texte de loi $n^{0} 27275$ sur l'accès à l'information, adopté en 2016. À cet égard, notre intention est de décrire le contenu du texte juridique en soulignant les aspects les plus fondamentaux de la législation, mais aussi de revoir le processus législatif de la norme susmentionnée. C'est-à-dire, on analysera le texte finalement approuvé, et aussi les différentes positions développées dans la discussion parlementaire, laquelle a entrainé différents avis et opinions de la part de divers législateurs. Nous ferons également référence aux opinions que divers groupes liés à la communication et au droit ont exprimées, concernant le droit d'accès à l'information. Pour faire la description, nous estimons d'abord nécessaire d'analyser conceptuellement le droit d'accès à l'information, étant entendu que ce concept n'est pas seulement opérationnel pour ceux qui travaillent dans les médias de communication sociale, mais aussi son plein exercice -á travers la garantie de l'État- a pour conséquence un plus grand et meilleur exercice de la citoyenneté.

Mot-clés: Accès à l'information, droit à l'information, participation politique, citoyenneté

摘要: 本文的目的是分析2016年通过的第27,275号信息获取法的案 文。从这个意义上讲, 我们的目的是描述法律案文的内容, 强调最基 本的方面法规, 但具有上述规范的立法程序也将受到审查。就是说, 最终批准的案文, 将对在议会讨论中提出的不同立场和不同立法者 的不同立场进行分析。同样, 我们还将参考一些意见, 即与传播和 法律有关的若干团体已就获取信息的法律表达了意见。为了进行描 述, 我们认为首先有必要从概念上分析信息获取权, 同时要了解, 这 一概念不仅仅对那些在社交媒体上工作的人有效, 而且通过国家保 证的充分行使，它可以更好地行使公民权。

关键字: 信息访问权-信息权-政治参与-公民身份 


\section{Introducción}

El debate parlamentario y la posterior sanción de la Ley de Acceso a la Información $\mathrm{n}^{\circ} \mathbf{2 7 . 2 7 5}$ que se sancionó en el año 2016 constituye un acontecimiento muy importante en materia de libertad de expresión en Argentina.

El objetivo de este atrabajo es precisamente analizar los contenidos de esa norma legal e intentar determinar si la misma es adecuada según los estándares que se han elaborado a nivel interamericano. Pero también realizaremos un análisis de las distintas posturas que se suscitaron en el Congreso Nacional a la hora de debatir el proyecto que oportunamente enviara el Poder Ejecutivo Nacional.

Para realizar el segundo de los análisis, tomamos los dictámenes de la Cámara de Diputados de la Nación que en general mostraron algún tipo de disidencia al proyecto del ejecutivo, intentando reflejar aquellas cuestiones que cuestionaron o al menos problematizaron sobre algunos de los contenidos de ese proyecto. Con respecto al Senado de la Nación, realizamos el mismo ejercicio, pero basándonos en el debate realizado a la hora de aprobar el mencionado proyecto.

A la vez también relevamos algunas de las opiniones que presentaron organizaciones de la sociedad civil que fueron convocadas por la Cámara de Diputados para que expresen su visión sobre lo que entonces era el proyecto que había enviado al Congreso el Poder Ejecutivo. Entendemos que más allá de la valoración que realicemos sobre el contenido de la ley tal como fue aprobada, las diferentes observaciones y aportes realizados por los legisladores y las organizaciones de la sociedad civil constituyen insumos más que apropiados para continuar con el debate sobre el derecho al acceso a la información e incluso pueden ser tomados en cuenta a la hora de diseñarse posibles reformas.

Pero el presente artículo parte de definir primero que implica desde el punto de vista teórico el derecho de acceso a la información. En ese sentido, se analizará el mencionado derecho como una manifestación del derecho a la información, como un 
instrumento para la consagración de un régimen democrático y un derecho para la participación ciudadana.

Finalmente y luego de brindar un panorama sobre la aplicación de la ley objeto de nuestro trabajo, en las conclusiones daremos nuestro punto de vista sobre la efectiva vigencia del derecho de acceso a la información y cuales deberían ser algunas de las acciones para que ese derecho pueda ser ejercido por el conjunto de la ciudadanía.

\section{II.1. El acceso a la información como manifestación del derecho a la información}

Señalan Courtis y Abramovich (2000) que el concepto de acceso a la información constituye un correlato directo con la libertad de expresión y el derecho a la información. El derecho de acceso a la información es una parte fundamental del derecho a la información, es decir, que sin el primer de esos derechos no se materializaría el segundo.

De hecho la redacción del artículo $13^{\circ}$ de la Convención Americana de Derechos Humanos expresa esa idea al señalar que: "Toda persona tiene derecho a la libertad de pensamiento y de expresión. Este derecho comprende la libertad de buscar, recibiry difundir informaciones e ideas de toda indole, sin consideración de fronteras, ya sea oralmente, por escrito o en forma impresa o artística, o por cualquier otro procedimiento de su elección".

El abordaje que se realiza del acceso a la información se sitúa en una primera instancia en el plano de justificación de los derechos individuales "en el marco de los llamado derechos de libertad o derechos de autonomía, dirigidos a sustentar el espacio de autonomía personal de los individuos y a permitirles la realización de un plan de vida que se ajuste a su libre decisión" (Abramovich y Courtis; 2000:225). Seguidamente los autores señalan que el derecho de acceso a la información cumple la función de esparcir el campo de autonomía personal, permitiendo el ejercicio de la libertad de expresión en un contexto de mayor diversidad de datos, voces y opiniones. 
Los autores también analizan la dimensión colectiva que tiene el derecho de acceso a la información en el sentido que cobra un carácter público y social que excede el factor de autorrealización personal. En ese sentido conciben a ese derecho "como mecanismo o andamiaje de control institucional, tanto frente a autoridades públicas como frente a particulares cuya situación de poder de injerencia o inducción permite la determinación de conductas de otros particulares o su misma subordinación" (Abramovich y Courtis; 2000:227).

En ese sentido, va a existir una fuerte vinculación entre una visión participativa de la democracia y el respeto de los derechos fundamentales como fuente de legitimación del ejercicio del poder.

El acceso a la información pública se funda en una de las características fundamentales de los gobiernos republicanos como es la publicidad de los actos de gobierno y la transparencia de la administración pública. Courtis y Abramovich señalan que "el acceso a la información sobre la cosa pública posibilita a las personas opinar con propiedad y veracidad, contribuyendo de tal modo al debate público de las ideas que es garantía esencial del sistema democrático. Les permite además investigar los problemas de la comunidad, controlar a los mandatarios y participar en la vida política del Estado" (2000:227).

La Corte Interamericana destaca la relevancia política de la libertad de expresión en los siguientes términos, según se expresa en la Opinión Consultiva 5/81: "En su dimensión social la libertad de expresión es un medio para el intercambio de ideas e informaciones y para la comunicación masiva entre los seres humanos. Así como comprende el derecho de cada uno a tratar de comunicar a los otros sus propios puntos de vista implica también el derecho de todos a conocer opiniones y noticias. Para el ciudadano común tiene tanta importancia el conocimiento de la opinión ajena o de la información de que disponen otros como el derecho a difundir la propia."

Es decir, que cuando se restringe ilegalmente la libertad de expresión, no sólo es el derecho individual de una determinada 
persona el que se está violando, sino también se afecta el derecho de toda/os a recibir informaciones e ideas.

\section{II.2. Derecho de acceso a la información como instrumento para la consagración de un régimen democrático}

El acceso a la información surge además como garantía para la socialización de la información y por ende como límite a su exclusividad. Así es como el acceso a la información sobre lo público puede facilitar a las personas a opinar, garantizando lo esencial del sistema democrático, lo que permite además investigar los problemas de la comunidad, controlar a quienes están en el poder y participar de la vida política del Estado; y como consecuencia de este derecho es que surge la obligación del Estado de evitar establecer restricciones que impliquen discriminación en el acceso a la información.

El derecho de acceso a la información hace al funcionamiento mismo de la democracia y deviene del principio de publicidad de los actos de gobierno como carácter esencial del sistema republicano. Cuando nos referimos a publicidad en los actos de gobierno, hacemos referencia a la divulgación que los funcionarios públicos deben hacer sobre la gestión que se les ha delegado.

Pierini y Lorences (1999:85) señalan que "El pueblo debe estar bien informado, en forma permanente, de los actos de quienes ejercen funciones públicas". Además, mencionan aquí importancia que tiene ese aspecto en un Estado de derecho y, como tal, no puede quedar librada a la voluntad de aquellos que se desempeñan en la función pública, por ello, la obligación de permitir el acceso a la información deberá transformarse en un elemento ineludible e inherente al correcto desempeño de la función. Agrega Bravo (2007: 125) además que no se puede restringir "todo aquel mensaje cuyo contenido es de incumbencia de todos los ciudadanos, y por ello, en principio, debe ser conocida por todos. El derecho protege aquí la publicidad y la libre circulación de la información a fin de que sea accesible a todos en forma efectiva". 
La transparencia y la publicidad en los actos gubernamentales son elementos determinantes del derecho de acceso a la información pública, que hoy constituye una de las condiciones necesarias para el funcionamiento adecuado de los sistemas democráticos. Reconocer el derecho de acceso a la información y hacer efectivo su ejercicio es un parámetro de suma importancia al momento de evaluar el grado de transparencia del que goza una sociedad (Basterra, 2012: 61).

Como lo afirman también, Nápoli, Vivot y Worman ${ }^{3}$, el acceso a la información es "un aspecto central de la vida democrática ya que instaura un derecho básico y, además, una condición principal para el ejercicio pleno de la ciudadaní".

El derecho al acceso a la información fomenta la autonomía de las personas, y permite a la vez la realización de un plan de vida que se ajuste a la libre decisión de las personas como hemos expresado, es por esto que los individuos pueden proteger sus derechos y prevenir abusos de parte del Estado, así como luchar contra males como la corrupción y el autoritarismo. Tiende además a proporcionar un mecanismo de control institucional, frente a autoridades públicas como a particularidades cuya situación de poder permite la determinación de conductas de otros particulares o su misma subordinación.

Por esto, es que el acceso a la información permite cubrir no solo derechos individuales sino también colectivos, jugando de esta manera la democracia como factor indispensable para el establecimiento de una sociedad, en la que se puedan desarrollar los valores humanos. A esto se refiere Loreti (1997) al señalar que aumentar la transparencia es un modo de garantizar el acceso a la información que se encuentra en poder del Estado, y cuanta existe mayor acceso a la información, más vigorosamente se insertará una comunidad en la discusión de los asuntos públicos.

3 En Pierdini y Lorences (2006:15) 
El acceso a la información debería ser entendido como un instrumento indispensable para afianzar el régimen republicano de un gobierno. Señalan Nápoli, Vivot y Worman ${ }^{4}$ que "por lo menos tres factores deben confluir para que el acceso a la información pública funcione como un componente de transformación y cambio social: la institucionalización del derecho a acceder a la información pública en las normas locales, provinciales y nacionales, junto con el cumplimiento real por parte de los distintos gobiernos y, particularmente, el ejercicio ciudadano de utilizar un derecho que se basa en el sentido común".

Cuando hablamos de un instrumento indispensable para afianzar el régimen republicano, no podemos dejar de mencionar aquí dos principios rectores, el de máxima divulgación y el de buena fe, según se consigna en Informe de la Relatoría de la Libertad de Expresión del año 2011.

Por un lado, el principio de máxima divulgación, se refiere al derecho de buscar, recibir y difundir informaciones, es decir, que el Estado se encargue de garantizar que toda la información sea pública y accesible, haciendo referencia a que haya una máxima publicidad, de tal manera que cualquier información en manos de instituciones públicas sea completa, oportuna y accesible.

Es así que, el principio de máxima divulgación -explica Eliades (2013:20)- "ordena diseñar un régimen jurídico en el cual la transparencia y el derecho de acceso a la información sean la regla general, sometida a estrictas y limitadas excepciones". Toda negativa debe ser motivada y corresponde que el Estado pruebe que la información que se solicita no puede revelarse, y refiere que ante una duda o un vacío legal, debe primar el derecho de acceso a la información.

Por otro lado, el principio de buena fe implica según Eliades garantizar el ejercicio de acceso a la información, es decir, que será esencial que los sujetos obligados a brindar la información

4 En Pierdini y Lorences (2006:16) 
actúen de buena fe, que interpreten la ley de manera tal que sirva para cumplir los fines perseguidos para la aplicación del derecho, y promuevan el principio de trasparencia.

\section{II.3. Un derecho para la participación ciudadana}

La información es una herramienta poderosa que abarcan distintos aspectos que se vinculan con el derecho a la participación de los ciudadanos en un sistema democrático. Sobre esto harán mención Abramovich y Courtis (2000), afirmando que el acceso a la información puede cumplir diferentes funciones para la sociedad.

Por un lado, como reclamo, es decir, "cuando el objeto central del reclamo es la información en sí misma”, es decir, que la información reclamada no tiene un carácter instrumental, sino que el derecho se satisface con la obtención de los datos y ejemplifican el derecho a la verdad como derecho a la información, señalando el derecho que tienen los familiares de personas desaparecidas a conocer el destino de éstas, y por ello el Estado debe satisfacer ese derecho con los medios que tenga a su alcance. También, lo ejemplifican con el derecho de acceso a datos personales, en el que el objeto de reclamo está centrado en la propia información o la libertad de investigación, donde el acceso a la información se justifica simplemente como vía de obtención de datos.

Por otro lado, señalan a la información como instrumento de otros derechos, que se refiere a la obtención de información no como fin en sí mismo, sino como instrumento de concreción de otros derechos, valores o principios, poniendo como ejemplo la información como presupuestos de mecanismos de participación, sosteniendo que la información no se dirige exclusivamente a evaluar la actividad del gobierno, sino que funciona como presupuesto del ejercicio del derecho a participar en la formación de políticas públicas o en la toma de decisiones públicas, como ocurre en las audiencias públicas para readecuar las tarifas de los servicios públicos. 
Asimismo, toman como ejemplo la información como presupuesto de mecanismos de fiscalización de la autoridad pública, es decir, referido al rol fiscalizador que la publicidad de los actos de gobierno concede a los ciudadanos representados bajo un gobierno democrático. ${ }^{5}$

Otra función es la información como presupuesto de exigibilidad de un derecho, en especial los denominados derechos sociales, esa exigibilidad estará supeditada a la definición previa de las obligaciones concretas del Estado. Ante esto, se presenta un problema, ya que resulta imposible realizarlo sin información previa acerca del contenido exacto de la obligación estatal sin conocer previamente el estado de goce de un derecho social como lo es la salud, la vivienda, la educación, entre otros. De modo tal, afirman Abramovich y Courtis, que la falta de información frustra las posibilidades de su exigibilidad, ya que resulta imposible establecer una comparación entre una situación anterior y la posterior de adopción de medidas por parte del Estado. Un ejemplo de esto es la necesidad de un informe de impacto ambiental previo a la realización de obras que puedan afectar el medio ambiente. ${ }^{6}$

La cuarta y última función es la información como presupuesto del ejercicio de un derecho, el cual resulta ser una condición indispensable para el ejercicio de un derecho - autonomía. La información funciona como presupuesto de la posibilidad de una decisión racional por parte del titular de un derecho. Aquí

\footnotetext{
5 "Un ejemplo de esta función fiscalizadora lo constituye el acceso o publicidad de las declaraciones patrimoniales de los funcionarios públicos al momento de acceder a su cargo, que se justifica en tanto mecanismo de evaluación de trasparencia y legalidad de la gestión individual de esos funcionarios" (Abramovich y Courtis; 2000:234). Además afirman que otro de los ejemplos que pueden resultar útiles para la comprensión de esa conceptualización es la utilización de información como mecanismo de evaluación de los resultados de políticas públicas.

6 Otro ejemplo "información de consumidores y usuarios, en los casos en los que se establecen parámetros de calidad del producto o servicio, tales como la protección de la salud y seguridad y la calidad y eficiencia de los servicios públicos" (Abramovich y Courtis; 2000:238).
} 
explican, que en muchos casos el orden jurídico concede a los particulares un marco de posibilidades de acción o elección, y el ejercicio efectivo del derecho sólo tiene sentido en la medida de la existencia de información previa que haga posible una verdadera elección. Esto último, se encuentra relacionado directamente con la función de la información como presupuesto de exigibilidad de un derecho.

\section{La Ley $\mathbf{N}^{\circ} \mathbf{2 7 . 2 7 5}$ de acceso a la información pública}

La referida ley se sancionó en la Argentina el 14 de septiembre de $2016^{7}$ y, tal como se expresa en su primer artículo, tiene por objeto "garantizar el efectivo ejercicio del derecho de acceso a la información pública, promover la participación ciudadana y la transparencia de la gestión pública" y se basa en una serie de principios generales que en caso de potenciales conflictos entendemos que garantiza el pleno ejercicio del derecho de acceso a la información. ${ }^{8}$

Se expresa a través del artículo $2^{\circ}$ que el derecho de acceso a la información pública comprende "la posibilidad de buscar, acceder, solicitar, recibir, copiar, analizar, reprocesar, reutilizar $y$ distribuir libremente la información bajo custodia de los sujetos obligados enumerados en al artículo $7^{\circ}$ de la presente ley, con las únicas limitaciones y excepciones que establece la norma.

\footnotetext{
7 La discusión parlamentaria que culminó con la sanción de la ley que estamos analizando se originó a partir de un proyecto de ley que presentó el Poder Ejecutivo Nacional cuyo texto fue modificado. El secretario de asuntos políticos e institucionales dependiente del Ministerio del Interior, Obras Públicas y Vivienda de la Nación, Adrián Pérez sostuvo al presentar el proyecto que "es una herramienta que promueve la participación ciudadana (...) el control de la ciudadanía sobre los actos de gobierno, y que ayuda a un ejercicio pleno del derecho a la libertad de expresión. Para que haya libertad de expresión tiene que haber una contracara, que es un buen acceso a la información. En Espin Di Febo (2017) entre otras cuestiones se sistematizaron y analizaron los diferentes proyectos legislativos que abonaron a la discusión parlamentaria.

8 En ese sentido la ley enumera y explica los alcances de cada uno de los principios que se señalan: Presunción de publicidad, transparencia y máxima divulgación, informalismo, máximo acceso, apertura, disociación, no discriminación, máxima premura, gratuidad, control, responsabilidad, alcance limitado de las excepciones, in dubio pro petitor, facilitación y buena fe.
} 
Se presume pública toda información que generen, obtengan, transformen, controlen o custodien los sujetos obligados alcanzados por esta ley."

Consideramos que el concepto que se utiliza es bien amplio por lo que abarca una serie de posibilidades para efectivamente garantizar y poder ejercer el derecho de acceso a la información, a la vez que se señalan quienes son las entidades que están obligadas y se establecen taxativamente las posibles limitaciones para el ejercicio de ese derecho.

En ese sentido, en el artículo $7^{\circ}$ se expresa quienes son los sujetos obligados a brindar información, entre los que se incluyen a la administración pública nacional -que comprende además a los organismos descentralizados-, el Poder Legislativo y los órganos que funcionan en su ámbito, el Poder Judicial de la Nación, los Ministerios Públicos Fiscal y de la Defensa, el Consejo de la Magistratura, el Banco Central.

También se incluyen a las empresas y sociedades del Estado y las que el Estado tenga participación minoritaria -sólo sobre esa participación-, como así también los concesionarios, permisionarios y licenciatarios de servicios públicos o demás cuestiones que correspondan al ejercicio de la función administrativa delegada.

Como sujetos obligados el referido artículo comprende además los entes jurisdiccionales en que el Estado nacional tenga participación, las personas jurídicas públicas no estatales, fideicomisos y entes cooperadores sobre los recursos públicos recibidos.

El inciso j) también incluye a las organizaciones empresariales, partidos políticos, sindicatos, universidades y cualquier entidad privada a la que se le hayan otorgado fondos públicos, siempre en relación a la utilización de esos fondos.

Hasta la sanción de la presente ley regía el decreto $1172^{9}$ del año 2003 que sólo abarcaba al Poder Ejecutivo Nacional, por lo

9 Además de leyes específicas como la ley 25.152 de Administración Federal de los Recursos Públicos que en su artículo $8^{\circ}$ establece que "La documentación de carácter físico y financiero producida en el ámbito de la Administración Nacional (...) tendrá el carácter de información 
que consideramos que la enumeración que hace la presente ley de las diferentes instituciones estatales que son sujetos obligados, además de aquellas instituciones que si bien no son estatales pero reciben fondos públicos también están obligadas a brindar información sobre el destino de esos recursos son aspectos muy positivos, sobre todo si tenemos en cuenta que el artículo que estamos analizando considera que el incumplimiento de lo que establece la ley será considerado causal de mal desempeño.

Pero además, los artículos 28 y 30 de la ley establecen que cada uno de los sujetos obligados deberá nombrar un responsable de acceso a la información pública dentro de su jurisdicción. Es decir, se determina que en el ámbito del Poder Legislativo, Poder Judicial, en los Ministerios Públicos y en el Consejo de la Magistratura a partir de los noventa días de publicada la ley se deberán crear un organismo cada uno que se encargará de recibir y tramitar las solicitudes de información en sus respectivos ámbitos.

La ley bajo el título de "Transparencia activa" determina que la mayoría de los sujetos obligados para facilitar la búsqueda y el acceso a la información a través de su página oficial deberán volcar las informaciones más relevantes de una manera accesible.

Habíamos expresado que se establecen excepciones. El artículo $8^{\circ}$ las señala taxativamente y se refieren a cuestiones que resultan razonables. ${ }^{10}$

pública y será de libre acceso para cualquier institución o persona interesada en conocerla" y la ley 25.831 de Régimen de libre acceso a la información ambiental. Durante el gobierno de Macri también se sancionó el decreto 117/2017 "Plan de Apertura de Datos", mediante el cual se propende a la "disponibilidad de los datos públicos en condiciones adecuadas para su uso y reutilización constituye un elemento catalizador para el fortalecimiento del proceso democrático, el desarrollo de políticas públicas basadas en la evidencia, la provisión de servicios públicos centrados en el usuario, y la promoción del desarrollo social, económico, científico y cultural de la Nación", según se expresan en los fundamentos del decreto.

10 a) Información expresamente clasificada como reservada o confidencial o secreta, por razones de defensa o política exterior; b) Información que pudiera poner en peligro el correcto funcionamiento del sistema financiero o bancario; c) Secretos industriales, comerciales, financieros, científicos, técnicos o tecnológicos cuya revelación pudiera perjudicar el nivel de competitividad o lesionar los intereses del sujeto obligado; d) Información que comprometa 
En ese sentido entendemos que las restricciones que se plantean no entran en colisión con lo que plantea la Relatoría Especial para la Libertad de Expresión (2012:12): "En atención al principio de máxima divulgación, la ley debe garantizar que el acceso a la información pública sea efectivo y lo más amplio posible, y en caso de contemplar excepciones, éstas no deben convertirse en la práctica en la regla general. Asimismo, el régimen de excepciones debe ser interpretado de manera restrictiva $y$ toda duda debe resolverse a favor de la transparencia y el acceso".

Es importante destacar que al finalizar el artículo que se refiere a las excepciones se expresa: "Las excepciones contenidas en el presente artículo no serán aplicables en casos de graves violaciones de derechos humanos, genocidio, crímenes de guerra o delitos de lesa humanidad".

El artículo $4^{\circ}$ establece el principio de legitimación activa, ya que tanto las personas humanas como las jurídicas, públicas o privadas, tienen derecho a solicitar información no pudiéndose exigir al solicitante que motive esa solicitud, o que acredite

los derechos o intereses legítimos de un tercero obtenida en carácter confidencial; e) Información en poder de la Unidad de Información Financiera encargada del análisis, tratamiento y transmisión de información tendiente a la prevención e investigación de la legitimación de activos provenientes de ilícitos; f) Información elaborada por los sujetos obligados dedicados a regular o supervisar instituciones financieras o preparada por terceros para ser utilizada por aquellos y que se refieran a exámenes de situación, evaluación de su sistema de operación o condición de su funcionamiento; g) Información elaborada por asesores jurídicos 0 abogados de la administración pública nacional cuya publicidad pudiera revelar la estrategia a adaptarse en la defensa o tramitación de una causa judicial o divulgare las técnicas o procedimientos de investigación de algún delito u otra irregularidad o cuando la información privare a una persona del pleno ejercicio de la garantía del debido proceso; h) Información protegida por el secreto profesional; i) Información que contenga datos personales y no pueda brindarse aplicando procedimientos de disociación, salvo que se cumpla con las condiciones de licitud previstas en la ley 25.326 de protección de datos personales y sus modificatorias; j) Información que pueda ocasionar un peligro a la vida o seguridad de una persona; k) Información de carácter judicial cuya divulgación estuviera vedada por otras leyes o por compromisos contraídos por la República Argentina en tratados internacionales; I) Información obtenida en investigaciones realizadas por los sujetos obligados que tuviera el carácter de reservada y cuya divulgación pudiera frustrar el éxito de una investigación; m) Información correspondiente a una sociedad anónima sujeta al régimen de oferta pública. 
algún interés legítimo o derecho subjetivo, o que deba contar con un patrocinio letrado.

Se tiene en cuenta la gratuidad en su artículo $6^{\circ}$ al determinarse que toda la información que es requerida es sin costo, a excepción de su reproducción. Además se establece el principio de informalidad al señalarse en el artículo $9^{\circ}$ que la solicitud de información se podrá "realizar por escrito o por medios electrónicos y sin ninguna formalidad a excepción de la identidad del solicitante".

Sobre los plazos para obtener la información solicitada el artículo $11^{\circ}$ señala que "toda solicitud de información pública (...) debe ser satisfecha en un plazo no mayor a quince (15) días hábiles. El plazo se podrá prorrogar en forma excepcional por otros quince (15) días hábiles de mediar circunstancias que hagan razonablemente difícil reunir la información solicitada. En su caso, el sujeto requerido debe comunicar fehacientemente, por acto fundado y antes del vencimiento del plazo, las razones por las que hace uso de tal prórroga".

Si se le negara la entrega de la información al solicitante, el artículo $14^{\circ}$ indica que existen dos vías de reclamo, la judicial y la administrativa, sin que se requiera agotar la instancia administrativa para reclamar judicialmente, pudiéndose interponer un amparo para ejercer el derecho que consagra la ley.

Otro de los aspectos fundamentales de la ley es la creación de la Agencia de Acceso a la Información Pública. El artículo 19 establece que la agencia será un ente autárquico y funcionará con autonomía funcional en el ámbito del Poder Ejecutivo Nacional. Sus funciones serán las de velar por el cumplimiento de los principios y procedimientos que determina la ley, garantizar el efectivo ejercicio del derecho de acceso a la información pública y promover medidas de transparencia activa.

La agencia estará a cargo de un director que será nombrado por el Poder Ejecutivo Nacional mediante un procedimiento de selección público, abierto y transparente que garantice la idoneidad del candidato, según lo que determina el artículo 20 
de la ley, que también determina el forma para la selección del director, los requisitos y las incompatibilidades del mismo.

Su mandato durará por cinco años -teniendo la opción de ser reelegido por única vez- y sólo puede ser removido de su cargo por mal desempeño, por delito en el ejercicio de sus funciones o por crímenes comunes mediante la realización de un procedimiento que se establece en el artículo 27.

También se determina la creación del Consejo Federal para la Transparencia como organismo interjurisdiccional de carácter permanente, cuyo objetivo será el de cooperar técnicamente y concertar políticas en materia de transparencia y acceso a la información pública. Tendrá su sede en la Agencia de Acceso a la Información Pública y estará integrado por representantes de cada una de las provincias y de la Ciudad de Buenos Aires y será convocado y presidido por el Director de la Agencia de Acceso a la Información Pública.

Entendemos que la sanción de la presente ley constituye un acontecimiento muy positivo ya que salda una deuda pendiente en materia de libertad de expresión y constituye un aspecto muy importante para el ejercicio del derecho a la información.

También del análisis de su contenido, surge que ley en cuestión constituye una herramienta idónea para poder hacer efectivo el derecho de acceso a la información en virtud de sus postulados. En ese sentido, entendemos que su texto contiene en general aquellas cuestiones que desde la OEA se han promovido a través de la Ley Modelo. ${ }^{11}$

Basterra (2017), quién en su trabajo valora positivamente el contenido de la ley que analizamos, expresa que el reconocimiento del derecho de acceso a la información a través de ese texto implica la concreción por añadidura de otros derechos fundamentales.

11 Ley Modelo Interamericana sobre Acceso a la Información de la OEA, aprobada por AG/ Res. 2607 (XL-0/10), del 8-6-2010, http://www.oas.org/es/sla/ddi/docs/AGRES_2607_XL0-10_esp.pdf. 
En ese sentido conlleva el reconocimiento y garantía de contribuir a la formación de una opinión pública libre, cuestión que se vincula el pluralismo político; permite la concreción del derecho a la libre expresión en su totalidad, ya que posibilita "acceder" a conocer como paso previo para la libre expresión; incide a favor del principio de autonomía personal, ya que se facilita la posibilidad de contar con más información para que cada persona pueda elegir; asegura la participación ciudadana en la toma de decisiones de la "cosa pública", y por ende es determinante para el ejercicio de la democracia participativa, así como de la tutela efectiva de los derechos económicos, sociales y culturales; permite el pleno ejercicio del principio de publicidad de los actos de gobierno y redunda a favor de la concreción del principio de transparencia de los actos de la administración, de gestión y de gobierno, indisolublemente ligado al control democrático sobre la actividad administrativa que deben realizar los habitantes de una nación; y, permite que la ciudadanía ejerza un verdadero control sobre el gobierno.

\section{Críticas y aportes a la discusión}

\section{IV.1. La discusión en el Congreso de la Nación}

Si bien en general el proyecto que presentó el Poder Ejecutivo tuvo una amplia aceptación, varios legisladores mostraron su disconformidad con algunos de los postulados que se plantearon. A continuación reflejamos algunas de esas disidencias fundamentalmente a través del análisis de los dictámenes de los diputados:

Dictamen de los Diputados Gustavo Arrieta, Alejandro Abraham, Carlos Castagneto, Eduardo de Pedro, Luis Cigogna, Marcos Cleri, Diana Conti, Ana Gaillard, Adrián Grana, Carlos Kunkel y Analía Rach Quiroga: Se afirma que el derecho de acceso a la información en poder del Estado constituye un pilar fundamental del sistema democrático de gobierno y del Estado de derecho en el que hoy vivimos. Y esto es así, sostienen, porque uno de los fines que persigue el derecho de acceso a la 
información pública consiste en permitir que todas las personas puedan tener a su alcance la información pública veraz y precisa en poder de los órganos del Estado a fin de poder participar en la vida democrática de éste.

Aquí es donde los diputados comienzan con su primera disidencia del proyecto de acceso a la información pública presentado por el Poder Ejecutivo fundamentando que "el mantenimiento del sistema democrático no se agota en el mero conocimiento por parte de los particulares de la información que poseen o controlan los órganos del Estado a fin de controlar su actividad. Muchas veces la toma de una decisión requiere de la conjunción de una multiplicidad de factores y de información que excede el mero ámbito del gobierno involucrando información en manos de particulares siempre que la misma cumpla con determinadas características y no sea para fines individuales. Si el acceso a la información se configura como un derecho colectivo la información cobra un marcado carácter público o social".

Asimismo, hacen mención en su dictamen a que cuando nos referimos al acceso a la información pública se debe situar el foco de atención no en el poseedor de la información sino en la naturaleza de la información que se requiere, señalando que la regulación de este derecho debe buscar permitir una mayor participación de todas las personas en los asuntos de interés público, y esto sólo se puede lograr si se garantiza a todas las personas el acceso a toda aquella información cuyo contenido sea de interés general.

Por eso, proponen incorporar en el artículo $7^{\circ}$ del proyecto "sujetos obligados" a las entidades privadas que, con o sin fines de lucro, tengan un fin público o posean información pública ${ }^{12}$.

12 El presente dictamen también proponía incorporar al inciso g) del artículo $7^{\circ} \mathrm{con}$ el fin de lograr mayor transparencia acerca de todo patrimonio estatal, debería abarcar a la totalidad de las empresas en las que el Estado tenga capital accionario o participación en la formación de decisiones y evitar la limitación a una participación mayoritaria por parte del Estado, afirmando que debería incluir a "las empresas, sociedades del Estado, las sociedades anónimas con participación estatal mayoritaria, las sociedades de economía mixta y todas 
Dictamen Diputados Juan Pedrini, Jorge Franco y Analía Rach Quiroga: Proponen un acceso más transparente y para que la ley sea lo más representativa posible plantean una autoridad de aplicación diferente, que sea colegiada con representación política, judicial y académica.

También sostienen que la autoridad de aplicación debe quedar a cargo de una comisión de acceso a la información, integrada por cinco miembros: un comisionado a propuesta del Poder Ejecutivo Nacional, designado con acuerdo del Honorable Senado de la Nación por mayoría simple; un comisionado propuesto por uno o varios diputados y elegido por la Honorable Cámara de Diputados de la Nación, por mayoría simple; un comisionado propuesto por uno o varios senadores y elegido por el Senado, por mayoría simple; un comisionado por el ámbito académico propuesto y elegido por el Consejo Interuniversitario Nacional y; un comisionado por el Poder Judicial a propuesta de la Corte Suprema de Justicia de la Nación, designado con acuerdo del Senado por mayoría simple. Destacando que cada comisionado durará cinco años en su cargo, pudiendo ser reelecto una vez.

También proponen que la presidencia de la comisión sea rotativa con duración de un año, considerando que se puede lograr una representación más amplia y garantía verdadera para las autoridades que velan por el derecho a la información. ${ }^{13}$

Dictamen Diputados Néstor David y Pablo Kosiner: Se propone una redacción alternativa de diferentes artículos. Por ejemplo en el $8^{\circ}$ que se clarifique a través de qué instrumentos jurídicos pueden determinarse las excepciones, en el artículo $9^{\circ}$ agregar quién es el responsable de emitir la respuesta ante la solicitud de información, que deberá ser la máxima autoridad

\footnotetext{
aquellas otras organizaciones empresariales donde el Estado nacional tenga participación en el capital accionario o participación en la formación de decisiones societarias", cuestión que finalmente pudo plasmarse en el texto definitivo de la ley.

13 También el dictamen hacía referencia a la posibilidad que se pueda reclamar vía acción de amparo, algo que finalmente el texto definitivo de la ley contempla.
} 
del organismo o entidad requerida, del artículo $15^{\circ}$ proponen que para facilitar la presentación de los reclamos cuando se trate de sujetos requeridos en lugares donde no haya delegación de la Agencia de Acceso a la Información Pública, deberá posibilitarse la presentación del mismo ante el sujeto requerido, a fin de no obstaculizar o dificultar el derecho a efectuar los reclamos, debiendo remitirse el mismo a la Agencia de Acceso a la Información Pública en un plazo de cinco días.

También señalan que es necesario incorporar en el artículo $17^{\circ}$ un motivo para fundamentar el rechazo de los recursos por incumplimiento para los casos en que los mismos se fundamenten en la entrega parcial de la información, a efectos de que la Agencia de Acceso a la Información Pública evalúe la integralidad de la respuesta y se expida al respecto. $\mathrm{Y}$ en el artículo $27^{\circ}$ se propone la incorporación de miembros de la oposición a la conformación de la comisión que conforme la autoridad de aplicación ${ }^{14}$.

Dictamen Diputados José Gioja y Héctor Tomas: Los diputados plantean que se profundice acerca de la condición de información reservada o clasificada, para lo cual probablemente haría falta pensar en un nuevo proyecto de ley específicamente ligado a esta materia. Además, manifestaron no estar de acuerdo con la autoridad de aplicación ${ }^{15}$.

Dictamen Diputados Hugo Marcucci y Mario Barletta: Los diputados proponen adicionar en el artículo $6^{\circ}$ que los costos no podrán exceder los valores reales de reproducción de la información requerida. Y en el artículo $7^{\circ}$ agregar en la enumeración

\footnotetext{
14 También se proponía en ese artículo la siguiente redacción que finalmente fue receptada en forma positiva: "Artículo 27: Remoción del director de la Agencia de Acceso a la Información Pública. El funcionario a cargo de la Agencia de Acceso a la Información Pública podrá ser removido por mal desempeño, por delito en el ejercicio de sus funciones o por crímenes comunes".

15 Con respecto al artículo $11^{\circ}$ en relación al pedido de información consideran que debe consignarse un plazo de quince días desde la presentación del particular, independientemente de la remisión del pedido que realicen los organismos intervinientes, algo que finalmente fue receptado.
} 
de los sujetos pasivos, a las provincias y municipios, y sus respectivos poderes y órganos, como también al final incorporar que la información considerada como reservada permanecerá con tal carácter hasta un período de 10 años. El período de reserva podrá extenderse sobre cierta documentación cuando permanezcan y se justifiquen las causas que le dieron origen.

Con respecto al artículo $9^{\circ}$ sugieren adicionar que será responsabilidad de la autoridad de aplicación instrumentar los medios necesarios para garantizar el ejercicio regular del presente derecho al solicitante que no pueda o no sepa darse a entender por escrito. Proponiendo además agregar al final que los sujetos pasivos, no podrán invocar ninguna de las excepciones enumeradas en esta ley cuando la información solicitada se refiera a violaciones de derechos humanos o sea relevante para investigar, prevenir o evitar violaciones de los mismos, cuestión que como expresamos se tuvo en cuenta en el texto de la ley.

Por otro lado, con respecto al artículo $18^{\circ}$ indican la incorporación de la responsabilidad de entes privados, explicando que serán sancionados con multa de $\$ 1.309$.273 a $\$ 261.864$.600, esto sin perjuicio de la responsabilidad civil y penal en la que pudieran incurrir las personas físicas requeridas.

Además, se refieren también a la autoridad de aplicación de la ley, sugiriendo agregar que no podrán ser designados quienes en los últimos diez años hayan ocupado cargos públicos con responsabilidad jerárquica en los órganos que se encuentran como sujetos pasivos de la ley. Además se propone modificar la forma de designación y remoción de los directores de la autoridad de aplicación, proponiendo agregar al final del título III "Los sujetos pasivos enumerados en la presente ley deberán contribuir a la generación de información de calidad, a su gestión, procesamiento para la generación de conocimiento, y evaluación de la gestión pública, así como también incentivar la promoción del derecho de acceso a la información y la cultura de la transparencia y su accesibilidad. 
De la misma forma, Mercucci y Barletta agregan que "deberán proponer al Ministerio de Educación la inclusión de contenidos sobre la importancia social del derecho de acceso a la información en los planes y programas de estudio en todos los niveles educativos; promover la inclusión de actividades curriculares y extracurriculares en los programas de estudio de instituciones educativas públicas y privadas que generen interés y participación en la temática; promover la instalación en las bibliotecas públicas y populares de todo el país ordenadores informáticos que faciliten el ejercicio del derecho derivado de las obligaciones de transparencia a que se refiere esta ley." ${ }^{16}$

Dictamen Diputada Ana Carrizo: Propone modificaciones en el artículo 23 que define los requisitos e incompatibilidades, indicando la exclusión de la edad puesto que constituye un acto discriminatorio e infundado, así como también el requerimiento de título universitario. Lo que debe considerarse y probarse es la idoneidad. También con respecto al director a designar la diputada propone que la condición del mismo es no haber desempeñado cargos electivos.

\section{IV.2. El rechazo al proyecto}

Diputado Néstor Pitrola: fue el único que se mostró en disconformidad en su totalidad con el proyecto de ley presentado por el Poder Ejecutivo. Su fundamentación parte de considerar que el proyecto que se estaba discutiendo no se basaba en consagrar el acceso a la información pública, sino que la característica principal era la consagración de las excepciones, consignadas en su artículo $8^{\circ}$, de un conjunto de secretos que hacen a la esencia de un Estado opuesto a la sociedad y sus derechos, y que obstruyen la participación de ésta en la toma de decisiones en defensa del interés nacional, y de los trabajadores que producen su riqueza social.

16 En el artículo $24^{\circ}$, inciso q), proponen modificar la redacción por la siguiente manera "Establecer las sanciones administrativas pertinentes en los casos de incumplimiento de las disposiciones de la presente ley", algo que finalmente se plasmo en el texto legal. 
Afirma que el artículo $8^{\circ}$ "se exceptúa de proveer la información cuando sea considerada como reservada o confidencial o secreta, por razones de defensa o política exterior. De acuerdo a esta excepción no podríamos pedir por la apertura de los archivos sobre el atentado a la AMIA acaecido hace 22 años, tal como las organizaciones de familiares de las víctimas vienen reclamando (...) la apertura de los mismos podría develar que el atentado a la AMIA fue el emergente de un sistema que entrelaza en la ilegalidad, la corrupción, la conspiración y el terrorismo y el papel que jugaron efectivamente una serie de protagonistas".

Del mismo modo, hace referencia al mismo artículo cuando se exceptúa de brindar la información a lo que pudiera poner en peligro el correcto funcionamiento del sistema financiero o bancario, fundamentando que se está buscando defender el secreto bancario por el cual se fuga dinero a cuentas suizas o las revelaciones de los Panamá Papers. Por esto, es que explica que es necesario derogar el secreto bancario, para empezar el de las entidades estatales y los funcionarios públicos.

Del mismo modo, siguiendo con el mismo artículo que establece las excepciones, Pitrola afirma que "otra muestra de lo que constituye la privación real del acceso a la información está planteada en la excepción sobre secretos industriales, comerciales, financieros. Por este inciso el gobierno estaría autorizado a mantener el secreto del acuerdo colonial YPF-Chevron".

Además, hace referencia que el proyecto de ley se trata de una ley ornamental democratizante, para maquillar a un Estado que cada día se evidencia como más conspirativo, más represivo y más imbricado y dependiente de los grupos económicos.

Por esto, Pitrola va a proponer los contenidos mínimos que debería contener un proyecto de ley para democratizar la obtención de información pública. Menciona que se debe proceder a la apertura de los archivos de la totalidad de los organismos de la administración pública y de las fuerzas de seguridad del Estado, así como de las empresas y sociedades del 
Estado, que abarcan a las empresas del Estado, las sociedades del Estado, las sociedades anónimas con participación estatal mayoritaria, las sociedades de economía mixta y todas aquellas otras organizaciones empresariales donde el Estado nacional tenga participación mayoritaria en el capital o en la formación de las decisiones societarias; sin excepciones de ningún tipo.

También, manifiesta que se debería establecer la anulación del secreto bancario para la banca pública y privada y disponer la apertura de sus libros; prohibir el secreto industrial y promover la apertura de los libros de las empresas privadas al control de sus trabajadores; transferir el control del INDEC a una comisión electa por sus trabajadores que abra la información procesada por el instituto al escrutinio popular (sindicatos, federaciones estudiantiles, etcétera).

De igual forma, se debería proceder a la apertura de los libros de la ANSES a comisiones de control elegidas democráticamente por los jubilados y trabajadores activos; abrir el conjunto de la información de todos los entes autárquicos y empresas estatales (YPF, FF.CC., Aerolíneas, etcétera) al acceso ciudadano, a través de comisiones de control elegidas democráticamente por sus trabajadores y usuarios; asistencia obligatoria de los funcionarios, incluidos ministros y eventualmente el presidente de la Nación, a citatorios de interpelación por la Cámara de Diputados; apertura de los libros de registro de las comisarías a comisiones vecinales electas democráticamente y crear una agencia de acceso a la información pública independiente del Estado, electa por voto popular.

\section{IV.3. El debate en el Senado}

Cuando el proyecto Ley de Acceso a la Información Pública pasó a la Cámara de Senadores, en el debate realizado el 6 de septiembre de 2016, se solicitaron varias modificaciones al proyecto aprobado en la Cámara de Diputados. El más importante fue referido a los sujetos obligados a brindar la información, donde varios manifestaron que no deben estar exentos aquí 
las sociedades anónimas con participación estatal mayoritaria, donde fue tomado como ejemplo explícito el caso YPF - Chevron.

La Senadora Carmen Crexell señaló, que si "YPF no quiere dar información, que se ampare en las excepciones que están contempladas respecto de la calidad de la información y no de la naturaleza del sujeto". ${ }^{17}$

El Senador Fernando Solanas, se expresó también con respecto al caso: "YPF es una sociedad con mayoría estatal y, además, los argentinos pagamos seis mil millones de dólares para recuperar el 51 por ciento de YPF. Y lo que eso oculta es el objetivo de sacar del control público" y, además señaló que "si nosotros sacamos del control público las grandes operaciones que realizan las empresas públicas o las empresas sociedades anónimas con mayoría estatal, la verdad que no sé qué es lo que nos queda, porque YPF ha escapado al control de la Auditoría General de la Nación". ${ }^{18}$

Asimismo, sostuvo que el proyecto tal como fue girado por la Cámara de Diputados necesita correcciones, y fundamenta que, no se puede negar acceso a la información pública de las contrataciones que realicen las empresas del Estado: "cuando se oculta la información de grandes contratos, el contrato de Chevron-YPF (...) no se oculta por los problemas técnicos geológicos y la fórmula de la Coca Cola, sino porque hay manejos y cláusulas lesivas al interés de la Nación." ${ }^{19}$

Ambos senadores manifestaron que se debería sacar el inciso $\mathrm{m}$ ) del artículo $8^{\circ}$ "información cuyo acceso requiera un procedimiento específico previsto por una ley dictada con anterioridad a la sanción de la presente".

Otro punto controversial fue la designación y remoción del Director de la Agencia de Acceso a la Información Pública. El Senador Alfredo Héctor Luenzo manifestó que el director de la

\footnotetext{
17 Versión Taquigráfica Cámara de Senadores (7 de septiembre de 2016).

18 Versión Taquigráfica Cámara de Senadores (7 de septiembre de 2016).

19 Versión Taquigráfica Cámara de Senadores (7 de septiembre de 2016).
} 
Agencia es designado por el Poder Ejecutivo, pero puede ser removido por una bicameral, fundamentando, que si puede esa bicameral removerlo por qué no designarlo. También se referirá a la representación de la Agencia, proponiendo que no sólo sea del Poder Ejecutivo, sino también del Legislativo y el Judicial.

Ante esto, el cambio que se establece es que el Director de la Agencia seguirá siendo designado por el Poder Ejecutivo, pero con acuerdo del Senado de la Nación.

Por otro lado, también se eliminó el artículo que destaca que podrá ser designado como Director quien haya ejercido cargos políticos o partidarios.

Por todo lo planteado en la Cámara de Senadores el proyecto con modificaciones se remitió a la Cámara de Diputados, y el 14 de septiembre de 2016, dicha Cámara rechazó las modificaciones propuestas y aprobó la Ley de acceso a la información pública con 186 votos a favor y sólo 16 en contra.

\section{IV.4. Opinión de las organizaciones de la sociedad civil}

Creemos importante destacar que algunas organizaciones levantaron su voz con respecto al proyecto inicial que presentó el Poder Ejecutivo. Muchos colectivos defensores de los derechos humanos y ONGs plantearon modificaciones al texto original del proyecto, fundamentando que tenían como objetivo lograr un mejor acceso a la información pública.

Desde el Centro de Estudios Legales y Sociales (CELS) entre varias modificaciones, se hacía referencia a la selección y remoción de los integrantes de la Agencia de Acceso a la Información Pública, donde consideraban que era necesario que la Agencia sea conducida por un cuerpo colegiado que asegure una representación más plural que la contenida en el proyecto del Ejecutivo y, en lo que respecta con la remoción de los directores, proponían que en el procedimiento intervenga una Comisión Bicameral, como finalmente se consignó en el texto de la ley. 
Otras organizaciones como la Asociación Civil por la Igualdad y la Justicia (ACIJ), el Directorio Legislativo, la Asociación de los Derechos Civiles (ADC), el Foro de Periodismo Argentino (FOPEA), la Fundación Conocimiento Abierto, Poder Ciudadano y Datos Concepción se manifestaron en conjunto y mostraron desacuerdos con algunos puntos del proyecto de la ley, entre ellos, hicieron mención a la falta de independencia que podía tener el Director de la Agencia de Acceso a la Información, ya que no se establecían garantías suficientes para asegurar la independencia e idoneidad de su titular, porque sólo existirá la remoción por causales de mal desempeño.

La justificación de la modificación se basaba en que esta regulación no brindaba las garantías mínimas de independencia necesarias para un órgano de control de esta naturaleza e importancia, al dejar en manos del Poder Ejecutivo la decisión sobre la remoción del titular de la Agencia, dado que el Poder Ejecutivo es un sujeto obligado a suministrar información, y a la vez tendría la potestad de designar y remover al órgano encargado de obligarlo a brindar información en caso de que se negara, contraviniendo el principio básico en materia de control público.

Dichas organizaciones sugirieron un proceso de designación que cuente con una instancia de concurso público de oposición y antecedentes y que, tanto en el caso del órgano garante del Poder Ejecutivo como del Legislativo, Judicial y Ministerio Público, se aseguren procedimientos de designación y remoción complejos que involucren la participación de más de un poder.

En referencia al artículo $23^{\circ}$, sobre los requisitos que debe cumplimentar el Director para ser designado, sugieren que la persona elegida debería no sólo tener título universitario o ser argentino, entre otros requisitos que se imponen, sino también demostrar antecedentes que acrediten la idoneidad para el ejercicio del cargo. Por ello, las organizaciones manifiestan que consideran necesario que se incorporen mayores precisiones para asegurar que el Director de la Agencia cuente con probada 
experiencia y trayectoria profesional en materia de acceso a la información pública, así como también un fuerte compromiso con la temática y con los valores democráticos.

Por otro lado, en relación a la negativa de entregar la información, al igual que varios legisladores y como finalmente quedó plasmado en el texto legal, se proponía expresamente a la acción de amparo como vía para realizar el reclamo, por considerar que se trata de la vía más adecuada y rápida para exigir la reparación de un derecho constitucional violado ante los actos u omisiones del Estado. ${ }^{20}$

También, hicieron referencia al artículo $28^{\circ}$ que establece que el Poder Legislativo, el Judicial, y el Ministerio Público crearán un organismo autónomo con competencias semejantes a los de la Agencia de Acceso a la Información, y sugieren aquí que sea la propia ley la que cree los órganos garantes en cada poder y no supeditar su creación, ya que fundamentan, el Congreso está facultado a hacerlo a través de esta norma sin afectar la independencia de otros poderes.

En relación al artículo $8^{\circ}$ que explicita las excepciones, se proponía la modificación de algunos incisos, entre ellos el referido a la información confidencial y reservada, donde manifestaron que era necesario que para considerar una información de ese tipo se exigiera la existencia de una ley que así lo indique, por ello proponían que la categoría de información secreta debería ser eliminada. También señalaron que el inc. b) referido a la información que pudiera poner en peligro el correcto funcionamiento del sistema financiero o bancario, se debería

\footnotetext{
20 Se expresaba que la acción de amparo permitiría evitar discusiones dilatorias en sede judicial respecto a la vía procesal correspondiente y seguiría la línea establecida en los casos "ADC c/ Estado Nacional - PAMI", “CIPPEC c/ Estado Nacional - Min. Desarrollo Social" y "Giustiniani, Ruben c/ YPF S.A. s/ amparo por mora", respecto a la admisibilidad del amparo como vía procesal más idónea. Y además señalan que servirá para asegurar más adecuadamente la tutela judicial el establecimiento de un procedimiento específico de amparo por acceso a información pública, que reduzca las formalidades necesarias para interponer la acción, acote los plazos de tramitación y resolución, y establezca expresamente la gratuidad de la vía judicial.
} 
establecer qué tipo información se trata y qué tipo de riesgos al correcto funcionamiento del sistema justificaría la restricción de la información, fundamentando que deberían haber mayores precisiones al respecto. En relación al inc. e.) vinculado a la información en poder de la Unidad de Información Financiera encargada del análisis, tratamiento y transmisión de información tendiente a la prevención e investigación de la legitimación de activos proveniente de ilícitos, sostuvieron que ese tipo de información a la que no se puede acceder públicamente debería ser acotada sólo a aquella cuya publicidad pudiera poner en riesgo real una investigación que se esté llevando adelante o esté protegida por el secreto fiscal o bancario.

Por otro lado, con respeto al artículo $9^{\circ}$ sobre solicitud de información, dichas organizaciones consideraron que no debería consignarse la identificación personal del requirente, ya que el último párrafo de dicho artículo establece que se entregará al solicitante una constancia del trámite, y que eso puede servir a los efectos del seguimiento y eventual judicialización del requerimiento. También, se refieren a las solicitudes de información, y explican que se debería contemplar además del medio escrito y electrónico, la presentación verbal u oral, en persona o por teléfono. Además, en relación al trámite proponen que por cada pedido de información, al requirente le sea asignado un número de expediente, para asegurar que el solicitante pueda realizar un seguimiento y eventualmente iniciar el reclamo.

Sobre el artículo $11^{\circ}$ que define los plazos propusieron que no se encuentran razones por las cuales el mismo deba ser extendido más allá de los diez días, fundamentando que quince son demasiados. Además, sobre el artículo $10^{\circ}$ donde se establece que, si el sujeto al que se dirige la solicitud no tiene competencia para responderla, éste deberá remitirla a la Agencia de Acceso a la Información Pública e informar sobre ello al solicitante, explican, no establece el plazo del que dispondrá el sujeto requerido para cursar esa solicitud al órgano correspondiente; por ello proponen que se debería establecer un plazo máximo para reenviar la solicitud al sujeto competente, período 
que no deberá superar la mitad de los días hábiles que establezca la ley para responder a los pedidos.

Por último, desde la Coalición por una Comunicación Democrática frente a la discusión parlamentaria se propuso que la autoridad de aplicación de la ley no fuera unipersonal sino un cuerpo colegiado compuesto por tres representantes de cada uno de los poderes del Estado, más un representante de la sociedad civil y otro del ámbito académico. Se proponía que el director de la agencia que crea la ley no sea el presidente del Consejo Federal asesor sino que sea otro de sus integrantes.

Sobre las acciones tendientes a la difusión del acceso a la información entre la población, desde la Coalición destacaron que "resultaba llamativo que el texto proveniente de la Cámara Baja contemplara como única acción la 'provisión [por parte de la Agencia] de un canal de comunicación con la ciudadanía', lo cual, explicamos, no resultaba preciso ni suficiente", además de señalar que en las capacitaciones que se planteaban no estaba claro si se realizarían para los empleados del organismo de aplicación o para los empleados de la administración en general.

Finalmente, en relación a los pedidos de acceso, se propuso que para el diseño de los trámites se tenga en cuenta el caso de los diferentes grupos sociales que poseen condiciones de vulnerabilidad "de modo que ningún impedimento físico, material o de acceso a las tecnologías de la información y la comunicación fuese un obstáculo para el pedido", haciendo hincapié a la cuestión de la accesibilidad.

\section{Excursus sobre la implementación de la Ley de Acceso a la Información}

Si bien el reconocimiento de un derecho a través de la sanción de una ley es un paso muy importante, sobre todo si la misma de acuerdo a su contenido efectivamente propende al ejercicio pleno del derecho, entendemos que para que ello ocurra también se debe analizar la implementación de la 
norma, es decir, se debe considerar cómo es la actuación del Poder Ejecutivo a la hora de efectivizar ese derecho. ${ }^{21}$

Pasados seis meses de la sanción de la ley 27.275, el ejecutivo nacional la reglamentó a través del decreto 206/2017. En el mismo se establece que la autoridad de aplicación de la ley actuará en el ámbito de la Jefatura de Gabinete de Ministros, haciéndose mención en el resto del decreto de diferentes cuestiones propias de una norma de esas características que no requieren mayor análisis ${ }^{22}$. Consideramos que la integración de la AAIP dentro de esa estructura es un retroceso ya que el artículo 19 de la ley tal como fue sancionada y promulgada la establecía "como ente autárquico que funcionará con autonomía funcional en el ámbito del Poder Ejecutivo nacional”.

Por otra parte, el decreto de necesidad y urgencia 746/2017 modificó la Ley de Ministerios y en lo que nos compete para nuestro análisis modificó la ley 27.275 estableciendo que la Agencia de Acceso a la Información se convierte también en la Autoridad de Aplicación de la Ley de Protección de Datos Personales 25.326.

21 Además por supuesto del análisis jurisprudencial. Entendemos que la jurisprudencia de la Corte Suprema de Justicia ha reconocido la vigencia del derecho de acceso a la información en los casos que ha intervenido, más allá que como hemos expresado existía solo un decreto referido a la información que se podía generar desde la administración pública. Ver por ejemplo los fallos:"Asociación de Derechos Civiles c/ EN PAMI (dto. 1172/03) s/amparo Ley 16.986, Buenos Aires, 4 de diciembre de 2012; "CIPPEC c/ EN - MO Desarrollo Social -dto. 1172/03 s/ amparo ley 16.986"; Buenos Aires, 26 de marzo de 2014; Giustiniani, Rubén Héctor c/ Y.P.F S.A. s/ amparo por mora", Buenos Aires, 10 de noviembre de 2015; "Garrido, Carlos Manuel c/EN AFIP s/ amparo ley 16.986", Buenos Aires, 21 de junio de 2016; Fallo caratulado "Stolbizer, Margarita c. EN - M. Justicia DD.HH. s/ amparo ley 16.986", Buenos Aires, 1 de septiembre de 2015; “Recurso de hecho deducido por la demandada en la causa Gil Lavedra, Ricardo Rodolfo c/ Estado Nacional - Ministerio de Justicia y Derechos Humanos - Inspección General de Justicia s/ amparo ley 16.986"; Buenos Aires, 14 de octubre de 2014. Desde la sanción de la ley que es objeto de nuestro trabajo no se han suscitado controversias en las que se haya expedido el máximo tribunal.

22 De todas formas es interesante que se establezca que toda información reservada, confidencial o secreta se mantendrá en ese estado durante diez años desde su producción, salvo que exista indicación en contrario. 
Transcurrido casi un año de la sanción de la ley, y luego que se realizara el procedimiento por ella previsto, a través del decreto 685/2017 se designó a Eduardo Andrés Bertoni como director de la Agencia de Acceso a la Información Pública, tal como había propuesto el Poder Ejecutivo Nacional.

El solo hecho que haya sido Relator Especial para la Libertad de Expresión de la Comisión Interamericana de Derechos Humanos de la OEA, entre otros antecedentes, implica que sea idóneo para el cargo y nos exime de mayores comentarios al respecto.

Si bien no cuenta con una página web específica, dentro del portal general del gobierno se puede acceder a la normativa, resoluciones, organigrama, el balance de gestión que el director debe presentar, tal como prescribe la ley, entre otras informaciones. $^{23}$

En el sitio web también se consignan los responsables de acceso a la información de las dependencias que constituyen los sujetos obligados según establece la ley y los responsables de las provincias, cuestión que creemos positivo ya que es una forma de que la ley se operativice. Se señala además mediante la confección de gráficos el nivel de cumplimiento de los diferentes organismos centralizados en cuanto a la transparencia activa, es decir, el nivel de publicación de los diferentes datos tal como prescribe la ley e hicimos referencia al describir el articulado.

Se consignan también los organismos ${ }^{24}$ que no cumplen con los requerimientos de acceso a la información como también

\footnotetext{
23 https://www.argentina.gob.ar/aaip

24 Al momento de culminar el presente trabajo (septiembre de 2019) los siguientes organismos han sido señalados por la propia AAIP por incumplir el pedido de acceso a la información: la AFIP en cinco oportunidades, la empresa Edesur, las Secretarías de Gobierno de Salud y General de la Presidencia, los ministerios de Educación y Seguridad, Radio y Televisión Argentina, Administración Nacional de Aviación Civil y el Banco de Inversión y Comercio Exterior. Se debe tener en cuenta, tal como se señala en la página web, que los sujetos obligados una vez que remiten la información luego de ser intimados y mencionados en el listado son retirados del sitio.
} 
se publican los dictámenes ${ }^{25}$ de los casos que si se resuelven, aunque no se publica la información que oportunamente se ha solicitado. Consideramos que al tratarse de información pública la misma debe ponerse a conocimiento de la ciudadanía en general, independientemente de quién efectúe el pedido, ya que al iniciar los trámites ante la AAIP se presume que esa información ha sido de difícil acceso.

En cuanto a los modos de solicitar información, se especifica que se puede realizar personalmente, vía correo postal o mediante la web.

En sentido, en Torres Molina (2018) se hacía referencia que para solicitar información vía web se debía contar con la clave fiscal que se solicita ante la Administración Federal de Ingresos Públicos, cuestión que despertaba dos tipos de reflexiones: Por un lado, ese requisito y esa modalidad no estaba consignada ni en la ley ni en el decreto reglamentario y no abonaba al principio de informalismo. Por otra parte, el hecho de que aquella/os que deseen ejercer el derecho de acceso a la información debían acudir al organismo recaudador implicaba problematizar sobre la concepción de ciudadanía en tanto se consideraba a los ciudadanos como tales en tanto sean consumidores, además que la propia AFIP no había respondido pedidos de acceso a la información. Pero ese procedimiento se simplificó y en la actualidad el pedido de información no se realiza mediante la clave fiscal, cuestión que celebramos.

El periodista Sebastián Lacunza en un artículo de mayo de 2018, además de señalar lo dificultoso que resultaba realizar un pedido de acceso a la información a través del mecanismo descripto anteriormente, relata el pedido que él mismo realizó para solicitar información a la ANSES sobre una comisión que ese organismo pagó a un fondo de inversión. Como las respuestas que brindó el organismo no fueron las adecuadas el periodista acudió a la AAIP que emitió un dictamen donde se señala que

25 Al 18 de julio del 2018 se han realizado 133 reclamos, dato que no figura en la web pero que desde la AAIP nos han comunicado vía correo electrónico. 
la pregunta fue contestada "de buena fe" y acusó al solicitante de pretender abusar de ese derecho.

En definitiva, en ese caso desde las diferentes instancias estatales no resolvieron el nunca esa solicitud de acceso a la información y si el periodista finalmente pudo averiguar el monto que pagó la ANSES en concepto de comisión -casi 2 millones de pesos- fue por otras fuentes y no por ejercer el derecho de acceso a la información.

A nivel judicial, encontramos en la causa "Murua, Manuel Eduardo y otro c/ EN s/ Amparo Ley 16.986" (Expte. $\left.\mathrm{N}^{\circ} 47456 / 2018\right)$ que 4 de octubre de 2018 la Sala III de la Cámara Nacional de Apelaciones en lo Contencioso Administrativo Federal dictó sentencia confirmando el rechazo de la demanda promovida por el actor y una cooperativa de trabajo (IMPA) con el objeto que el Poder Ejecutivo Nacional provea información pública vinculada con el empréstito contraído con el Fondo Monetario Internacional en junio de 2018.

No vamos a describir aquí las distintas instancias procesales que esa causa tuvo, pero nos parece importante resaltar que el rechazo al pedido de acceso a la información estuvo motivado por cuestiones de forma, en el sentido que quienes promovieron el amparo no agotaron la vía administrativa -ya nos hemos referido a esta cuestión al describir el articulado y el debate parlamentario- y el resultado en última instancia ha sido que el derecho que estamos trabajando en el presente artículo no ha sido garantizado ${ }^{26}$.

${ }^{26}$ En la demanda se afirma: "Lejos de olvidar que la ley en la materia exige acudir primero a la instancia administrativa, abordamos en extenso dicha exigencia para demostrar que en este caso, a modo de excepción, no correspondía su aplicación por su inutilidad y por la urgencia del caso. Entre otras cosas, ofrecimos prueba para demostrar que diversos funcionarios del PEN y legisladores del oficialismo habían afirmado públicamente que el crédito en cuestión no será sometido a aprobación del Congreso de la Nación en virtud de que la ley de administración financiera así lo permitiría por ser Argentina miembro del FMI (art. 60, último párrafo, de la Ley № 24.456). También señalamos que el PEN no ha puesto a disposición el expediente o los expedientes, ni el propio contrato, en base a los cuales se habría perfeccionado el empréstito. Y sostuvimos que para tener esa discusión social con 


\section{A modo de conclusión}

De los expuesto surge que la sanción de la Ley de Acceso a la Información Pública constituye acontecimiento muy positivo ya que salda una deuda pendiente en materia de libertad de expresión y del análisis de su contenido surge que ley en cuestión constituye una herramienta idónea para poder hacer efectivo el derecho de acceso a la información, más allá que los argumentos esgrimidos por legisladores que cuestionaron algunas de las omisiones que tuvo la ley -y que hemos señalado- la hubieran enriquecido, como así también los aportes que se realizaron desde las organizaciones de la sociedad civil.

El texto legal recoge los estándares elaborados por el sistema interamericano de derechos humanos y más allá de las críticas señaladas la implementación de la norma puede permitir el efectivo ejercicio de ese derecho.

El éxito o el fracaso de la ley dependerá de la ciudadanía en relación a si toma para sí esa herramienta para permitir el ejercicio de otros derechos, que en definitiva es el objetivo fundamental de la vigencia del derecho de acceso a la información.

Pero para que ello ocurra, es responsabilidad del Estado primero sensibilizar y difundir sobre la existencia de la ley, realizar campañas de concientización y difusión a través de diferentes dispositivos para que la ciudadanía primero conozca y luego se apropie de ese derecho, cuestión que a tres años de su sanción todavía está ausente. Y en segunda instancia, y también es responsabilidad estatal, capacitar a las diferentes

un mínimo de seriedad, era esencial (y lo sigue siendo) disponer de la información que peticionamos de manera urgente y sin exigirnos transitar por una instancia administrativa que, a la luz de dichas declaraciones y de la prueba acompañada en el expediente, se mostraba a todas luces inútil". Toda la información de esta controversia se encuentra en: https:// classactionsargentina.com/2019/04/30/la-sala-iii-de-la-cncafed-confirmo-el-rechazo-deun-pedido-de-acceso-a-informacion-publica-para-conocer-el-contrato-y-las-condicionesde-toma-del-credito-con-el-fondo-monetario-internacional-por-la-su/?fbclid=IwAR3jViuBO WaXkDxwJe7fMGXkv06ZmiGk_0jwIEJOc2nZTOD5gYs22vkmkXM 
estructuras gubernamentales para que puedan garantizar ese derecho y cumplir con sus obligaciones legales.

En ese sentido, si bien la sanción de una ley como la que describimos en este trabajo es un paso muy importante, su sola existencia no garantiza el real ejercicio del derecho de acceso a la información.

\section{Bibliografía}

Abramovich, Víctor y Courtis, Christian (2000): "El acceso a la información como derecho". En Duhalde, Eduardo Luis (Editor). Anuario de derecho a la comunicación. Buenos Aires, Siglo XXI de argentina editores. Catálogos, pp.223 - 256.

Basterra I. Marcela (2012): Conflicto entre derechos fundamentales: Derecho a la información vs Derecho a la intimidad. Rubinzal-Culzoni .

Basterra I. Marcela (2017) : La Ley 27.275 de Acceso a la Información Pública. Una deuda saldada. Revista de Derecho Público $\mathrm{N}^{\circ} 1$ (11-42) - Rubinzal Culzoni.

Bravo, Paula (2007): El derecho de acceso a la información pública es un derecho de incidencia colectiva- Revista Jurídica de UCES $\mathrm{n}^{\circ} 11$.

Cámara de Senadores de la Nación. Versión taquigráfica "Reunión Plenaria de las Comisiones de Asuntos Constitucionales, de Presupuesto y Hacienda y de Justicia y de Asuntos Penales". 1 de junio de 2016.

Cámara de Diputados de la Nación. Sesiones Ordinarias, Orden del día $\mathrm{N}^{\mathrm{o}}$ 23. Comisiones de Asuntos Constitucionales y de Presupuesto y Hacienda. 22 de abril de 2016.

Centro de estudios legales y sociales (CELS) (2016): "Propuestas de modificación al Proyecto de Ley de Acceso a la Información Pública" (Recuperado el día 10 del mes 09 de 2018 de http:// www.cels.org.ar/common/20160420\%20CELS_Propuestas_ modificaci\%C3\%B3n_Ley_Acceso_Informaci\%C3\%B3n.pdf).

Coalición por una Comunicación Democrática (2016): "Debate en torno a la sanción de la Ley 27.275 de Derecho de Acceso a la Información Pública". (Recuperado el día 10 del mes 09 
de 2018 de http://www.coalicion.org.ar/debate-en-torno-a-lasancion-de-la-ley-27-275-de-derecho-de-acceso-a-la-informacion-publica/)

Eliades, Analía (2013): "El derecho de acceso a la información pública. Derecho humano e indivisible y mecanismo de realización de la vida democrática”. En Diálogos de la comunicación (Felacacs), edición 87 diciembre.

Espin Di Febo, Elena: Comunicación social y derecho: un análisis de su relación a partir del derecho de acceso a la información. Tesina de grado para obtener la licenciatura en Comunicación Social, UNRN, 2017. Director: Javier Torres Molina.

Espin Di Febo, Elena; y Torres Molina, Javier (2018): “Acceso a la información: Un análisis de la ley 27.275”. Ponencia presentada en el Encuentro Nacional de Carreras de Comunicación (ENACOM 2018), organizado por la Federación Argentina de Carreras de Comunicación (FADECCOS) y la Universidad Nacional del Centro de la Provincia de Buenos Aires (UNICEN), Olavarría, 19 de septiembre.

Lacunza, Sebastián: "Acceso a la información: de la celebración inicial al laberinto y las trabas”. Letra P, 20 de mayo de 2018. (Recuperado el día 10 de junio de 2018 de: https://www.letrap. com.ar/nota/2018-5-20-12-11-0-acceso-a-la-informacion-de-lacelebracion-inicial-al-laberinto-y-las-trabas).

Loreti, Damián (1997): El derecho a la información. Buenos Aires: Paidós.

Pierini, Alicia y Lorences, Valentín (1999): Derecho de acceso a la información. Por una democracia con efectivo control ciudadano: Editorial Universidad, Buenos Aires.

Torres Molina, Javier (2018): Paradojas del acceso a la información. Suplemento La Ventana, Medios y Comunicación de Página 12, 25 de julio. (Recuperado el día 10 del mes 09 de 2018 de https://www.pagina12.com.ar/130596-paradojas-del-acceso-ala-informacion). 